\title{
Supporting World War I Heritage Digitisation and Presentation Through User-Centered Web Design
}

\author{
Tiansheng Shi \\ Department of Computer Science and Technology \\ University of Bedfordshire \\ Luton, LU1 3JU, UK \\ tiansheng.shi@study.beds.ac.uk
}

\author{
Haiming Liu \\ Department of Computer Science and Technology \\ University of Bedfordshire \\ Luton, LU1 3JU, UK \\ Haiming.liu@beds.ac.uk
}

\begin{abstract}
This paper presents a user-centered website design for a museum, which aims to engage local communities with museum digitisation and encourage residents to access and learn about their World War I (WWI) heritage in town. The interface design of the website follows human computer interaction (HCI) design guidelines and based on the review of existing WWI related websites. Considering the majority of users of the website are elderly people, the website especially provides features to support the elderly users. The website will not only contribute to the museum digital transformation project on WWI, but also improve the connection between the museum and the local community through widening the participation.
\end{abstract}

Keywords-World War I; Museum digitisation; HumanComputer Interaction (HCI); User-Centered System Design (UCSD); Website design

\section{INTRODUCTION}

As part of a digital transformation project, a user-centred website is required by a museum to engage local communities in learning World War I (WWI) culture heritage. The website enables the local communities to explore, learn and contribute to the WWI stories. The website records people, objects and events of WWI in town, which are remembered or experienced by today's residents and their families in the local communities.

Although this project is remarkable and meaningful for all people to acknowledge more about the WWI, the design of the website pays more attention to elderly users because we observe that majority of users of the site are elderly users during the market research stage.

A user-centred system design (UCSD) places the users, their goals, requirements, activities and context at the centre of the design process [1, 2]. A good UCSD requires a good understanding of the users through user modelling [3]. To the elderly users, the design and development of website must support them, especially to overcome their fears and enable them to accept technological aids without reservations [4]. Dickinson et al (2007) [5] stated special principles and methods should be applied when design for elderly user groups. For example, written documentation need to ensure readability. Font size should be enlargeable and language should be straightforward because older participants may have bad eyesight and some of them may have poor literacy skills to understand complicated words and sentences. Instructions need to be simple, clear and available all the time because many elderly users do not have experience to use a computer system and interface before, so that they need lots of support.

This paper presents a user-centred website of the museum digitisation project, where users can upload, browse and learn multimedia information about WWI. The multimedia information can be text, image and video. The design of the website does not only follows the human-computer interaction (HCI) design principles [1-3], especially the UCSD design guidelines for elderly users $[4,5]$, but also reflects to the review of the existing WWI related websites.

\section{LITERATURE REVIEW}

Human-computer interaction (HCI) is the interaction between man and machine, which means people interact with computers or machines that include computers essentially [6]. Interface design is very important in computer systems design process because the interface is the first contact point between the users and the systems. The users often judge whether the system is good or bad based on the effectiveness of the interface [7]. A good interface allows users to interact with the system effectively, which should be user-friendly, efficient, and intuitive [8]. User-friendly means that users feel comfortable when using the system and can perform the tasks effectively. Efficient means that users are able to perform the certain tasks with minimal effort and time as well as maximum speed. Intuitive means that users can realise how the system basically works all through instinct. A few HCI design principles will be reviewed below for effective interface design $[7,9,10]$, which will be applied to the proposed web interface design in Section IV.

Consistency - During interface design process, maintaining the consistency is significant. It allows users to transform existing knowledge into new tasks to gain new knowledge more quickly. The system should reinforce the user's expectations from any previous interaction with the system. Basically the interface should give no surprises so the users. The users should not have to guess what need to be done next or how to do it.

Predictability - The system interface should always advise the possible action that users will need to take next. The current state of the system should be explicit to the users, so that it is easy for users to predict what can be done next.

Adaptability - Interface should adaptable to users. For example the system can adapt to users' working speed. Further 
the interface also needs to adapt to the user skill levels, characteristics, etc. However, overdone adaptability may lead to the decrease of interface consistency.

Economy and error prevention - In order to minimum the necessary steps and save users' time and effort, an interface should be designed economically, such as, using short cuts in dialogue, etc. In addition, the interface should prevent users from making errors, such as, deleting all data without backup.

User control - Users would like to feel that they are controlling computers rather than being controlled by the system. For example, users can select operation mode and change the software system work environment and choose from optional functions etc.

Structure - an interface should be structured to decrease the complexity. For example, some software group similar functions together in a panel.

Intuitive - Information should be easy to understand and accept by users. Sounds and/or graphics can help users understanding on the content and action required by the users.

Timely response - Usually users can tolerance only for 3 seconds when there is no respond to the user's command. Feedbacks should be provided to the users if the system requires longer time to process the work.

Relevance - Redundant information should not be requested from users. Instead, system should require minimum of user input and present the minimum of system output necessary to complete the user's tasks.

Supportiveness - Similar to the relevance principle, supportiveness principle allows the system to provide adequate information for users to operate and perform their tasks, such as help and hint functions.

Flexibility - According to user's level of performance and preferences, the interface should accommodate differences to different users. Furthermore, the interface also needs to give several support levels and allow personalized output formats.

It is important that interface design follows the HCI design principles. It is also essential to apply user-cantered system design (UCSD) method when carry out the interface design. UCSD places the users, their goals, requirements, preferences and activities at the centre of the design process which is an iterative design process [1].

From the observation of the market research, it has been learnt that majority of the users of the WWI project are senior citizens. These users have very limited or zero digital literacy. They need their family members to help them access the WWI website. Therefore, the design of the website must support the elderly users, especially to overcome their fears, increase their confidence to use the website.

Some design principles and methods $[11,12]$ are developed especially for elderly users listed below:

Readability - Font size should be at least 14 point and language should be easy to understand, because elderly users may have problems with eyesight and some of them may have poor literacy to understand complicated words and sentences.
Instructions - Instructions is essential to elderly users because many of them do not have the experience to use a computer system or interface and need to spend more time to learn how to use it compared to younger users. Instructions can reduce the operation errors and make the operation more effective. And instructions should be clear and explicit. When difficult words need to be used, be prepared to repeat important instructions.

Timing - Senior users often take longer time to complete tasks and to achieve autonomy.

In addition to review the $\mathrm{HCI}$ design principles and UCSD mode, an examination of the related web site based on the design principles is also carried out in the following section.

\section{RELATED WeBsites REVIEW}

Eight related website are reviewed in light of the above design principles for elderly users in Table 1.

TABLE I. Related Websites ReView Based on HCI PRINCIPLeS

\begin{tabular}{|c|c|c|}
\hline Website & Advantages & Disadvantages \\
\hline $\begin{array}{l}\text { First Word } \\
\text { War }^{1}\end{array}$ & $\begin{array}{l}\text { The website is to provide a } \\
\text { summary overview of the First } \\
\text { World War which has well- } \\
\text { structured web pages and clear } \\
\text { and ease to understand labels. It } \\
\text { has a "about this site" page, which } \\
\text { reflected the relevance principle. }\end{array}$ & $\begin{array}{l}\text { The website is static } \\
\text { with busy interfaces. } \\
\text { The adaptability } \\
\text { principle is not well } \\
\text { engaged because users } \\
\text { cannot interact with the } \\
\text { interface freely. }\end{array}$ \\
\hline $\begin{array}{l}\text { War World } \\
\text { One } \\
\text { Battlefields }^{2}\end{array}$ & $\begin{array}{l}\text { It is a personal website to share } \\
\text { interests in WWI. This website } \\
\text { links to a twitter account and the } \\
\text { information about a particular } \\
\text { topic can be updated frequently } \\
\text { and further there is a search box } \\
\text { embedded on the home page } \\
\text { where the users can search for } \\
\text { related information. }\end{array}$ & $\begin{array}{l}\text { The category of the } \\
\text { content is not clearly } \\
\text { labeled and there is no } \\
\text { functions to support } \\
\text { elderly users based on } \\
\text { the design guidelines. }\end{array}$ \\
\hline $\begin{array}{l}\text { World War } \\
\text { Centenary }^{3}\end{array}$ & $\begin{array}{l}\text { This website is to collect and } \\
\text { present the WWI events. The } \\
\text { content in the website is clean and } \\
\text { clear and well presented with } \\
\text { short summary and option to } \\
\text { expand for more information. } \\
\text { Relevance principle is well used. }\end{array}$ & $\begin{array}{l}\text { Limited information } \\
\text { about the history and } \\
\text { events of WWI are } \\
\text { provided. No function } \\
\text { is provided to support } \\
\text { elderly users' adaptive } \\
\text { reading }\end{array}$ \\
\hline $\begin{array}{l}\text { Diary of } \\
\text { Mary Martin }\end{array}$ & $\begin{array}{l}\text { This website is a digitized diary of } \\
\text { Mary's WWI experiences. The } \\
\text { website is well structured and } \\
\text { informative - easy to find } \\
\text { information. It has "how to use" } \\
\text { tag and the tags are well } \\
\text { structured. }\end{array}$ & $\begin{array}{l}\text { No search function is } \\
\text { provided which limited } \\
\text { users' information } \\
\text { seeking activities. } \\
\text { There are no specific } \\
\text { functions for elderly } \\
\text { users. }\end{array}$ \\
\hline $\begin{array}{l}\text { Antwerp } \\
1914-1918^{5}\end{array}$ & $\begin{array}{l}\text { This website introduces the WWI } \\
\text { story in Antwerp. The website } \\
\text { includes multimedia information } \\
\text { plus animations and good } \\
\text { navigation method. Users are } \\
\text { allowed to choose language that } \\
\text { they prefer. Feeds from Facebook } \\
\text { and Twitter are provided. The }\end{array}$ & $\begin{array}{l}\text { The animations made } \\
\text { the switch between } \\
\text { pages very slow which } \\
\text { against the timing } \\
\text { principle. But it has a } \\
\text { loading indicator. there } \\
\text { are no functions for } \\
\text { elderly users on the }\end{array}$ \\
\hline
\end{tabular}

\footnotetext{
${ }^{1} \mathrm{http}: / / \mathrm{www}$. firstworldwar.com/

${ }^{2} \mathrm{http}: / /$ www.ww1battlefields.co.uk/

${ }^{3}$ http://www.1914.org/

${ }^{4}$ http://dh.tcd.ie/martindiary/

${ }^{5} \mathrm{http}: / /$ www.antwerpen 1914-1918.be/en
} 


\begin{tabular}{|c|c|c|}
\hline & $\begin{array}{l}\text { position and style of tags are very } \\
\text { well designed. A sliding style is } \\
\text { applied to information } \\
\text { presentation. Consistency } \\
\text { principle, adaptability principle } \\
\text { and flexible principle are well } \\
\text { engaged. }\end{array}$ & site. \\
\hline $\begin{array}{l}\text { War } \\
\text { Memorials } \\
\text { Trust }^{6}\end{array}$ & $\begin{array}{l}\text { The website contains War related } \\
\text { teaching material for different } \\
\text { school level, which aims to } \\
\text { protect and conserve war } \\
\text { memorials in the UK. Many } \\
\text { pictures with links are shown in } \\
\text { the home page that suits the } \\
\text { relevance principle and economy } \\
\text { principle. It saves users time and } \\
\text { make the page tidy at the same } \\
\text { time. Navigation path is providing } \\
\text { to show where you are on the site, } \\
\text { which is very useful. }\end{array}$ & $\begin{array}{l}\text { The site is text heavy. } \\
\text { Lots of scrolling up and } \\
\text { down need because the } \\
\text { information is quite } \\
\text { long on a page. }\end{array}$ \\
\hline $\begin{array}{l}\text { Imperial War } \\
\text { Museums }^{7}\end{array}$ & $\begin{array}{l}\text { This site is a war related website } \\
\text { that contains a page of WWI } \\
\text { information. The website is } \\
\text { multimedia rich with good } \\
\text { browsing speed. The categories } \\
\text { and menu are well structured and } \\
\text { clear. Small blocks on some of the } \\
\text { pages link to other pages which } \\
\text { match the relevance principle. }\end{array}$ & $\begin{array}{l}\text { The interaction between } \\
\text { the users and the } \\
\text { system is limited. }\end{array}$ \\
\hline $\begin{array}{l}\text { The } \\
\text { Cleveland } \\
\text { Museum of } \\
\text { Art }^{8}\end{array}$ & $\begin{array}{l}\text { This website is Art Museum } \\
\text { website that displaces the museum } \\
\text { artifact. The animation is well } \\
\text { used on the home page. Images as } \\
\text { links are used to save user's time } \\
\text { to navigate which matches the } \\
\text { timing principle and intuitive } \\
\text { principle. }\end{array}$ & $\begin{array}{l}\text { Some place holders are } \\
\text { used among the image } \\
\text { links, which does not } \\
\text { look good. Users can } \\
\text { get lost because of too } \\
\text { many layers of image } \\
\text { links, which breaks the } \\
\text { relevance and } \\
\text { predictability design } \\
\text { principle. }\end{array}$ \\
\hline
\end{tabular}

\section{Proposed WWI Website}

Based on the review of the design concepts and principles and the review of the related websites, a WWI website for the local museum is proposed in this section. The WWI website aims to collect and present digitised WWI related artefact (such as people, objects and events) from and to the local communities. The populated website will be a valuable resource for museum visitors and people who are interested in WWI and history.

Fig. 1 introduces the key features on the home page of the website based on the reviews that we have done in above Sections. As the website is part of the digital transformation project of a local museum, the design (such as colour scheme of the website) aligns with the design of the museum website 9 . Key 1: users can set their favorite page as home page and add pages into favorites. This function brings convenience to the users especially the elderly users who find difficult to browse the website and find the pages that they like.

\footnotetext{
${ }^{6} \mathrm{http}: / /$ www.learnaboutwarmemorials.org/

${ }^{7} \mathrm{http}: / /$ www.iwm.org.uk/visits/iwm-london

${ }^{8} \mathrm{http}: / /$ www.clevelandart.org/

${ }^{9} \mathrm{http}: / / \mathrm{www}$. lutonculture.com/
}

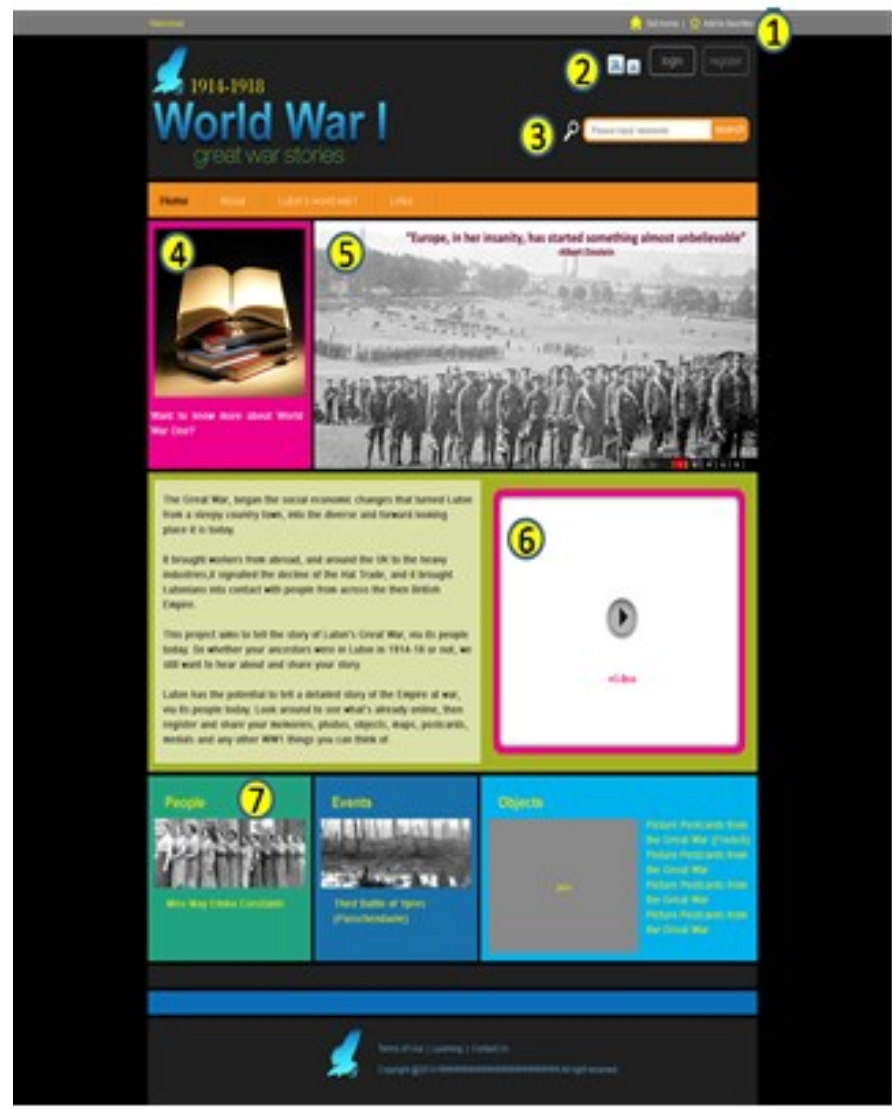

Fig. 1. Home page of the proposed WWI website

Key 2: users can change font size, which is especially useful to the users with vision difficulties. Key 3: a search function can assist users to explore more information online, which we consider is more suitable to more experienced digital platform users. Key 4: Luton Home Library Service ${ }^{10}$ makes people's booking borrowing easier, which is a service especially for the disabled and elderly citizens in the town. A book can be ordered online and delivered to home. It is considered to be a useful function to have on the digital museum website to support users' especially elderly users' exploratory learning. Users can find a list of books related to WWI held in the local library when they click on this section. Key 5: a slide show of the pictures of the new entries in the website, so that users can click on the pictures and jump to the pages to view the content. Key 6: a video provide a brief introduction about the project and the website, which provide an alternative form of the introduction to different user preferences from the text-based introduction on the left. Key 7: the three colorful blocks showing people, events and objects, which are the three main categories of the content in the website. This design provides the users especially the elderly users an intuitive and explicit view to the content.

The most of the design ideas developed from the review section have been applied to the design of the WWI website. However, due to time constrain and programming skill

\footnotetext{
${ }^{10} \mathrm{http}: / / w w w . l u t o n c u l t u r e . c o m / l u t o n-l i b r a r i e s /$ find-a-library/homelibrary-library-service/
} 
limitation, some of the good design practices are not implemented in the WWI website at this stage. For example, the website does not have links to Facebook and Twitter are not provided although having links to social media site, such as Facebook and Twitter does not only provide up to date information and communication service, but also increase the number of visit to the website; The website does not have function to switch between different languages although this function can be very useful considering people from different countries are interested in the history related to WWI; There is no animation used in the WWI website although the usage of animation may help engage the users.

\section{CONCLUSION}

This paper presents the design of a WWI website for a digital transformation project of a local museum. The website aims to record and present the WWI stories from the residents of the local community. As the majority of the users are elderly people, the design of the website has focused on the usercentred design for elderly users. Related design theories and websites have been reviewed for and reflected into the design of the WWI website. Although the prototype of the website is tested and working, there are still more work needs to be done in the future. For example, more function need to be added to the website. A user student needs to be carried out to evaluation the effectiveness and usability of the user-centred website.

\section{REFERENCES}

[1] Serengul, S. (2006) Human-computer interaction. Middlesex University Press.
[2] Preece, J., Sharp, H. and Rogers, Y. (2015) Interaction Design: Beyond Human-Computer Interaction, 4th Edition, John Wiley \& Sons.

[3] Adams, R. and Langdon, P. (2003). SIMPLEX: a simple user checkmodel for Inclusive Design. In Universal Access in HCI: Inclusive Design in the Information Society. Stephanidis, C. (Ed.). 4, 13-17. Mahwah: NJ: Lawrence Erlbaum Associates.

[4] Holzinger, A., Mukasa, S.K., Nischelwitzer, K.A. (2008) Introduction to the special thematic session: human-computer interaction and usability engineering for elderly (HCI4AGING). In Proc. Of ICCHP 2008, vol. 5105, pp.18-21.

[5] Dickinson, A., Arnott, J. and Prior, S. (2007) Methods for human computer interaction research with older people, Behavior \& Information Technology, 26(4), pp.343-352.

[6] Yang, X. \& Chen, G. (2009) 'Human-computer interaction design in product design', Education Technology and Computer Science, 2 (7-8), pp.437-439.

[7] Faulkner, C. (1998) The essence of human - computer interaction. Prentice Hall.

[8] Ceperley, D., Dandekar, S. \& Eddy, J. What is HCI. Available at: http://repo-

nt.tcc.virginia.edu/classes/200r/projects/fall_1999/hci/goals.html (Accessed: 2014).

[9] Pan, C. (2010) 'Human-computer interaction system design and implementation in network', Computer Engineering and Technology (ICCET), 7 (16-18), pp.V7-104-V7-107.

[10] Sutcliffe, A. G. (1995) Human-computer interface design. 2nd edn. Macmillan.

[11] Dickinson, A., Arnott, J. \& Prior, S., (2007) 'Methods for human computer interaction research with older people', Behavior \& Information Technology, 26 (4), pp.343-352.

[12] Andreas, H., Kizito, S.M. \& Alexander K. Nischelwitzer (2008) 'Introduction to the special thematic session:Human-Computer interaction and usability for elderly (HCI4AGING)', Springer-Verlag Berlin Heidelberg, pp.18-21. 